Enrique Bonavides Mateos

Seminario de Poética, IIFL, UNAM

\title{
Mujer y Espacio en el Islam
}

\section{La ciudad}

En el mundo islámico, todo espacio está orientado, dentro de su función específica, al intercambio dentro de la comunidad y a la comunicación de unos miembros con otros. Por consiguiente, si el espacio público, en la ciudad islámica, debe servir para la comunicación, ¿a qué leyes tendrá que atenerse entonces la relación entre el espacio privado y el espacio público? El sociólogo marroquí Mohammed Metalsi da a esta pregunta una respuesta interesante:

Si se quiere edificar una ciudad que responda a las ideas de la sociedad y la familia islámicas, esto significa que hay que crear un espacio con una forma material que traduzca una actitud del espíritu. Esta actitud del espíritu se expresa en la tendencia a construir casas y barrios que queden más o menos sustraídos a las miradas del exterior. Por consiguiente, hay que procurar por todos los medios esconder las casas, reducir al mínimo sus visitas al exterior, es decir, sus ventanas, y cerrar el espacio público con multitud de callejones. ${ }^{1}$

El tupido trenzado que de esta manera se crea, de esquinas, calles e innumerables callejones, extravía a cualquiera y le da

' Metalsi Medine, Ville essentielle, Casablanca, s/d,1980, p. 40. 
la sensación de hallarse perdido en un laberinto infinito, del que no hay manera de salir. Sin embargo, esa estructura urbana no es en realidad sino la traducción arquitectónica de un orden social específico en el que las relaciones entre lo exterior y lo interior, entre lo de afuera y lo de adentro, entre lo público y lo privado, lo masculino y lo femenino, se hallan reglamentadas con la mayor precisión y severidad.

En su enumeración de los conceptos con que se describe la "fisiología" del "tejido" urbano de la ciudad, es decir, los elementos que dan cuerpo y carne, sentimiento y alma a ese tejido, señala Malek Chebel:

Con sus ventanas, sus verandas acristaladas, sus balcones, azoteas y moucharabiahs (miradores con celosías de madera) que por su parte realizan la función de pestañas que pueden abrirse y cerrarse-, las murallas de sus ciudades, los tragaluces de sus bodegas, sus miradores y torreones adomados de arabescos, sus misteriosas celosías y los pozos que uno encuentra en todos los patios, con la luz que se refracta en los perfiles de los soportales, los rumores que salen del interior, y los enigmáticos aromas y perfumes, la ciudad se presenta como un cuerpo. $^{2}$

La cosmovisión del Islam, una religión que reglamenta hasta en sus menores detalles la vida cotidiana de sus fieles, plasmó de manera duradera la forma arquitectónica de todos los centros urbanos del ámbito islámico.

\section{El Suq}

En todos los lugares públicos -con excepción de la mezquita- el hombre está obligado a probar su virilidad, a demostrarla ante todo el mundo por la manera de mirar, de hablar y de

${ }^{2}$ Chebel Malek, Le corps dans la tradition au Maghreb, Parss, Payot, 1984, p. 132. 
caminar. En contraste con el hombre, a la mujer se la educa desde la infancia para que encubra su feminidad. Es controlada constantemente por padres y parientes para que no vulnere las leyes de la "honra" y de la castidad. Aun antes de que cumpla los diez años, se le inculca que debe evitar todo aquello por lo que pudiera perder su virginidad. Se le hace ver que el mundo fuera de la casa es un peligro incesante. Si está obligada a salir constantemente de casa, la muchacha tiene que cubrirse y ocultarse con un velo, convertirse en una sombra a la que es imposible tocar.

Allá donde cualquier otra forma de comunicación entre el hombre y la mujer está prohibida, el arte de la seducción se convierte en la única forma (estratégica) de tratarse. El escenario principal de esa estrategia de seducción fue desde siempre el suq.

En época preislámica había en La Meca un famoso mercado, el Suq Ukaz. En él se reunían todos los años, en tiempo de la peregrinación, los miembros de las diversas tribus, los comerciantes y las prostitutas de Arabia, para ofrecer sus "mercancías". Con los comerciantes acudían también a La Meca poetas procedentes de todas las regiones de la Península Arábiga. El Suq Ukaz era la tribuna en la que los poetas ensalzaban en extensos poemas laudatorios la grandeza, el poder y la virtud de sus respectivas tribus. Según la tradición, después del certamen poético, se esculpían en piedra con letras doradas los mejores poemas y las tablas se colgaban de las paredes de la kaaba. De ahí su nombre de mu'allaqat, las "colgadas". ${ }^{3}$ Ahora bien, con el tiempo, estos poemas fueron suplantados por textos del Corán que ahora se escriben en letras de oro sobre telas que cuelgan de la Kaaba

${ }^{3}$ Una colección de siete odas (casidas) de poetas preislámicos. Sin embargo, la denominación mu'allagat no aparece sino más tarde, y es, por tanto, de fecha más reciente que los poemas y la colección de los mismos. 
Parece como si el suq fuera la gran tribuna para la exhibición de la virilidad: cuanto más profundamente se penetra en la vida interna del suq, y más se deja uno embriagar por sus aromas y perfumes, tanto más hechizado se encuentra uno por un erotismo sutil que se halla presente en todas partes; el suq es $\mathbf{C}$ foro de la vida pública. Aquí no hay paredes ni tapias. Todo se ofrece a la vista de los compradores y de los que pasan. Y todo cuanto se produce, se exhibe allí orgullosamente. Es un enorme escenario de exhibición, un teatro colosal. El suq es corso, plaza y pasaje del mundo árabe. Es el lugar en que puede verse de todo y puede mostrarse de todo.

\section{La Casa}

Si el hombre es el dueño del espacio público, la mujer posee el control absoluto de la esfera privada, que es precisamente la casa. Más aún, en el mundo islámico, la casa se identifica con la mujer.

Además de los establecimientos sociales y religiosos de la ciudad que están institucionalizados, la casa —en árabe, dardesempeña un papel importante en la configuración del espacio islámico. El lugar central de la casa árabe, cuyas habitaciones se hallan dispuestas a diversos niveles entre la planta baja y la azotea, es el patio —en árabe, wasat ad-dar-, el centro de la casa. El patio, en general, es un recinto interior de forma cuadrangular, se halla a cielo abierto y no está protegido contra la lluvia ni contra el sol.

La estructura del espacio privado refleja claramente la organización de la vida pública. El interior de la casa se identifica con la esfera femenina, y por eso la arquitectura del dar se atiene al principio de cubrirse con un velo, de deslindarse del espacio público por un lado, y establecer una separación entre el recinto de los hombres y el de las mujeres, por otro. Para 
deslindar bien el ámbito privado del espacio público, "se cubren con velos" los "ojos de la casa", las ventanas, por medio de celosías de madera. La casa misma se protege, por medio de setos, de las miradas de las personas extrañas y de los vecinos.

Por eso, la puerta de la casa no conduce nunca directamente al interior de la vivienda, sino a un zaguán oscuro y cerrado, desde el cual no se puede ver el interior de la casa. Las casas grandes tienen a veces varias entradas y diversas escaleras, por las cuales se puede entrar desde las calles, pero sólo a ciertas partes de la casa.

En el interior de la vivienda continúa de manera rigurosa la separación de sexos que es corriente en el espacio público: hay habitaciones para las mujeres y habitaciones para los hombres, las azoteas son principalmente del dominio de la mujer; ahí es donde las tareas domésticas se realizan con "apertura femenina" y las mujeres pueden entablar relación directa con las vecinas de las casas colindantes; el hombre tampoco puede moverse libremente por el territorio femenino, sólo se le permite el acceso a la azotea en determinadas circunstancias y con ciertas precauciones; dispone de una "isla" en la propia casa, siendo el dueño principalmente de los recibidores (selamlik o diwan), en donde el señor de la casa puede recibir a los hombres que van a visitarle.

La mujer es quien da a la casa su "aura" y su alma; ambas cosas - la envoltura y el contenido - son a fin de cuentas una sóla. Interesarse por saber cómo se encuentra la "casa" no significa otra cosa en árabe que interesarse por saber cómo se encuentra la señora de la casa o preguntar por las demás moradoras de la casa. Esta identificación física con la mujer tiene como consecuencia una serie de normas rituales, por las que se protege el "cuerpo" de la casa de toda eventual impureza, principalmente cuando ese cuerpo ha entrado en contacto con personas extrañas del sexo masculino. 
El hammam y todo lo que se desarrolla en él, es parte de la "cultura islámica", y los baños públicos se cuentan entre los espacios más importantes de la ciudad.

Una descripción precisa del proceso de tomar un baño la tenemos en el tratado seudo-aristotélico Sirr al-asrar "El Misterio de los misterios" — de Abd al-Rahman Badawi, para quien El baño público:

se cuenta entre las cosas más notables que hay en el mundo, y entre las cosas más maravillosas que los sabios de la tierra han inventado y descrito para solaz y limpieza del cuerpo, relajación de los miembros, y apertura de los poros, purificación de los vapores y secreciones, y liberación de la piel de todo vestigio de dolor y enfermedad. Esto se logra porque el baño público está construido con arreglo a las estaciones del año, pues el espacio más caliente corresponde al invierno; el siguiente, al otoño; el que viene después, a la primavera, y el último al verano. Para bañarse como es debido, conviene que el bañista permanezca algún tiempo en el primer espacio; de ahí pase al segundo, y se quede en él poco tiempo, y luego entre en el tercero... Una vez llegado al tercer espacio, se echa en una hamaca acolchada hasta que el cuerpo comience a sudar. Luego se frota de vez en cuando el cuerpo con un paño de lino. Y, cuando ha sudado ya suficiente, entra en el recinto del baño, donde se lava (o: efectúa el ghusl, la gran ablución) y se mete en una bañera con agua entre tibia y caliente. Si el calor se ha apoderado bien de su cuerpo y él se ha calentado por completo, entonces necesita echar mano de un jabón que le lave a fondo, según la estación del año. Derramará sobre su cabeza agua moderadamente caliente; después se frotará bien el cuerpo para quitar la suciedad y la porquería; luego se ungirá con un aceite que corresponda a la época del año; a continuación se limpiará la piel derramando sobre ella agua clara o dándose las cremas apropiadas para este fin. Después volverá a entrar en una ba- 
ñera con dos compartimentos, el primero de los cuales tendrá agua más caliente. Finalmente, para salir seguirá el mismo procedimiento paulatino que acabamos de describir. A continuación se tumbará en el tercer espacio hasta que se haya "secado" (es decir, hasta que ya no sude). Se secará el cuerpo con paños perfumados con agua de rosas y ámbar. En verano se secará con toallas de lino blandas y finas, y en invierno, con toallas de algodón o de seda. Cuando tenga sed, beberá aproximadamente $1 / 2$ ratl (unos 200 gramos) de agua de rosas o de zumo de manzana perfumado con almizcle y mezclado con agua fría. Después se relajará, contemplando toda clase de bonitos cuadros pintados artísticamente, o —-mejor y con más aciertoa una persona de bello rostro, y mirará delicadas flores. Luego comerá, ingiriendo la cantidad corriente de bebidas mezcladas, pero nunca lo hará con exceso ni beberá nada embriagador. Después de esto, se perfumará con un perfume que corresponda a la estación del año, se acostará en un lecho blando y tratará de dormir. Inmediatamente después del baño y durante la noche siguiente, se abstendrá de tener trato carnal, para que éste no elimine los buenos efectos del baño que nosotros hemos planeado y realizado. 4

Ahora bien, hay que anotar que en muchos países árabes, ir al hammam significa preparase para el amor o purificarse de la "impureza" originada por él. El hammam es al mismo tiempo el preludio y terminación del acto sexual o, como lo formula Abdelwahab Bouhdiba:

El hammam es el epílogo del placer carnal y el prólogo de la oración. El ceremonial del hammam es presexual y postsexual. La sexualidad y la purificación se suceden mutuamente. El hammam aparece como el necesario intermedio entre el goce sexual, por el que el musulmán contrae impureza y pierde la tahara - la pureza ritual-, y el instante en que efectúa su

${ }^{4}$ Heinz Grotzfeld, Das Bad im arabisch-islamischen Mittelalter, Weisbaden, Günter-Verlag, 1970, pp. 141-143. 
oración, lee el Corán y, al recobrar la pureza, vuelve a sentirse seguro. El ceremonial del hammam es un acto de retomo a la espiritualidad, un ritual para serenar las tensiones físicas y psíquicas provocadas por el acto de hacer el amor. ${ }^{5}$

El baño era más que nada un lugar de vida social, Munawi, uno de los autores de los numerosos tratados que existen sobre el hammam, recomienda: "Hay que ir al baño acompañado de un grupo de amigos cultos e instruidos, que sepan historias, anécdotas y relatos, porque esto disipa las penas, serena el ánimo, alegra el corazón y prepara para el amor". 6

\section{El hammam: refugio de las mujeres}

El hammam era para las mujeres, un refugio. Los juristas, sólo permitían la entrada en los baños a las enfermas y a las puérperas, pero no podían impedir que las mujeres hicieran del hammam su dominio propio, un punto de evasión para su feminidad oprimida fuera de los muros de la casa.

En las grandes ciudades había casas de baños destinadas únicamente para mujeres. Pero generalmente se reservaba para ellas, en el hammam general, el tiempo que va desde la oración del mediodía hasta la primera oración del atardecer, mientras no se tratara de baños reservados exclusivamente para hombres, los cuales se hallaban casi siempre en el barrio de los bazares. En cuanto sonaba la hora para el baño de las mujeres, el personal masculino de servicio se sustituía por personal femenino, y mediante una toalla colgada a la puerta se daba a conocer que, desde aquel momento, se trataba de una "sociedad cerrada".

${ }^{5}$ Bouhdiba Abdelwahab, La sexualité en Islam, París, s/d, 1975, p. 203.

${ }^{6}$ Citado según Grotzfeld, op.cit., p. 4. 
A pesar de la prescripción, válida tanto para hombres como para mujeres, de llevar puesto en el baño un "taparrabos", las mujeres casi nunca cumplían estrictamente la disposición dada por los juristas. Uno de los autores de los tratados sobre el hammam, Ibn al-Hay, se irrita por la desvergüenza de las mujeres: "Entran en el baño con las partes pudendas descubiertas. Si sucede alguna vez que una mujer cubra sus partes pudendas desde el ombligo hasta las rodillas..., las demás mujeres se burlan de ella y le dicen palabras groseras hasta que logran que ella se descubra". ${ }^{7}$

Aunque las mujeres estaban generalmente desnudas en el hammam, en ese recinto se procedía con mucha moralidad. Se efectuaba la purificación ritual; las mujeres se lavaban a sí mismas y lavaban a sus niños, y pasaban la mayor parte del tiempo cuidando intensivamente de su belleza, sobre todo de la belleza de los cabellos y de la piel. Finalmente, el baño era principalmente para las mujeres un lugar de vida social y de contactos sociales. Por eso, tenía para ellas una importancia mucho mayor que para los hombres, los cuales podían satisfacer sus necesidades sociales en el bazar, en la mezquita y en los más diversos lugares de diversión. La desnudez y la proximidad corporal en el baño proporcionaba intimidad. No sólo relajaba los miembros sino que, principalmente, soltaba las lenguas.

El baño era, además, indirectamente, un lugar para concertar bodas. Allí, las madres de hijos casaderos buscaban la que pudiera ser su futura nuera, de cuyas condiciones físicas el marido no podría convencerse sino post festum. En la esfera íntima del baño, podía uno informarse despreocupadamente acerca de la fama que tuviese la muchacha, acerca de su familia y acerca de su "precio", es decir, del dinero que habría que pagar por la novia. Si la cosa va bien, entonces para el baño siguiente se invita a la familia de la muchacha, y en esta ocasión la suegra

${ }^{7}$ Ibid., p. 147. 
estudia personalmente a la "novia", con esponja y cepillo, para comprobar si todo está bien y no se descubre en el cuerpo de la chica ninguna mancha que no aparezca a primera vista.

También parte de los preparativos de la boda se realizan en el hammam. Uno o varios días antes de la boda, la novia es acompañada al baño, con gran alboroto y cánticos, por las amigas y familiares, Una de las muchachas lleva en un paquete o en un cesto todos los utensilios necesarios para el baño: tarros de cosméticos, cepillos, peines, jabones, perfumes, cera para depilar, comida y bebida... El proceso de lavado, frotado y masaje es realizado por una de las mujeres expertas, lo mismo que el proceso de depilación, que en las muchachas jóvenes se realiza por primera vez antes de la boda. Una vez terminado este complicado proceso, se conduce a casa a la novia entre gritos de alegría y cánticos de gozo. Esta ruidosa procesión de novia se llama hasta el día de hoy zaffat al-hammam que, traducido libremente, quiere decir: "la fiesta del baño (que tiene lugar antes de la boda)."

Como podemos observar, la división del espacio social en un ámbito público y masculino, y en un ámbito privado y femenino es expresión de las condiciones jerárquicas y de poder, porque el mundo islámico está subdividido estrictamente en dos mundos distintos: el universo de los hombres, la umma, al que corresponde el poder y la religión, y el universo de las mujeres, al que pertenecen la sexualidad y la familia. 